\title{
Fe-rich cap lithologies in the TAG hydrothermal field: implications for the preservation of extinct seafloor massive sulphide deposits
}

\author{
IAIN J. STOBBS ${ }^{1}$, PAUL A. J. LUSTY ${ }^{2}$, S. PETERSEN ${ }^{3}$, \\ SHIPBOARD PARTIES OF THE M127 AND JC138, \\ BRAMLEY J. MURTON ${ }^{1}$ \\ ${ }^{1}$ National Oceanography Centre, Southampton, UK, \\ Iain.Stobbs@soton.ac.uk, Bramley.Murton@noc.ac.uk \\ ${ }^{2}$ British Geological Survey, Environmental Science Centre, \\ Keyworth, Norringham, UK \\ plusty@bgs.ac.uk \\ ${ }^{3}$ GEOMAR, Helmholtz Centre for Ocean Research Kiel, \\ 24148 Kiel, Germany \\ spetersen@geomar.de
}

Three different extinct seafloor massive sulphide (eSMS) deposits within the TAG hydrothermal field were drilled and studied: Southern Mound, MIR Mound, and a newly discovered mound, named 'Rona Mound'. All three sites comprise a superficial sediment cover of carbonate over ironrich oxyhydroxides, underlain by a coherent and dense layer of red-coloured silica-rich 'jasper', tens of centimetres thick, overlying less altered massive sulphide. While silica replacement textures of the wall rock are described from modern hydrothermal systems [1], these do not form 'caps'. However, the association of similar iron-silica-rich strata overlying VMS deposits (the ancient analogue of SMS deposits) is well documented [i.e. 2]. The origins of the silica 'cap' is controversial with contrasting views on whether the silica is hydrothermal, hydrogenic or biogenic, and whether the iron is a direct product of sulphide weathering or derived from hydrothermal plume fallout.

We suggest that these 'jasper' layers are a common product, formed during the waning stage of the hydrothermal cycle. As a result, they form an impermeable 'cap' that protects the underlying massive sulphide ore body from ingress of oxygen-rich seawater and subsequent oxidation and dissolution. The formation of a 'jasper cap' acts automatically to preserve eSMS deposits when hydrothermal circulation ceases and is essential to the resource potential of eSMS deposits. This research received funding from the EC FP7 project Blue Mining (604500).

[1] Hannington, M., et al. (1998). Proceedings of the Ocean Drilling Programme, Scientific Results. 158. 389-415 [2] Slack, J.F., 2012, U.S. Geological Survey Scientific Investigations Report 2010-5070-C, chap. 10, 6 p. 